\title{
Quanta matemática escolar é conhecida pelos egressos dos cursos brasileiros de Licenciatura?
}

\author{
How much of High School mathematics do Brazilian future mathematics teachers \\ master?
}

\author{
Leonardo Barichello ${ }^{1}$ \\ Marcelo Firer ${ }^{2}$
}

\begin{abstract}
Resumo
Neste texto, buscamos interpretar o significado do desempenho de estudantes de licenciatura em matemática no ENADE para além dos conceitos divulgados pelo INEP. O caminho escolhido se baseou nos índices de acerto em questões objetivas de conteúdo matemático presentes na prova aplicada em licenciandos em matemática no ENADE 2017 de acordo com dois critérios. Consideramos as questões descritas pelo INEP como questões de Ensino Básico e complementamos a análise associando o conteúdo de algumas das questões dessa edição do exame com conteúdos de questões que compuseram o ENEM. As conclusões apontam que a grande maioria dos futuros professores de matemática chegam ao final da sua formação inicial sem domínio adequado sobre conteúdos notadamente de Ensino Médio, com preocupante nível de acertos a perguntas que, espera-se, seus futuros alunos sejam capazes de resolver.
\end{abstract}

Palavras-chave: Formação de Professores; Matemática; ENADE; Conhecimento de conteúdo

\begin{abstract}
In this paper we aim to better understand the meaning of future mathematics teachers' scores on the Brazilian National Higher Education Exam (ENADE). Our approach is based on the proportion of right answers on the multiple choice questions about mathematical knowledge applied to future mathematics teachers at ENADE 2017. First, we considere the proportion of right answers to questions whose content were identified by the creators of the exam as part of the curriculum of High School. Second, we complemented the analysis by comparing the knowledge required by a few questions in ENADE with the content of question in the National Exam for High School (ENEM). The conclusions highlight that the majority of future mathematics teachers get to the end of their initial education without developing knowledge on topics that will be taught on High School.
\end{abstract}

Keywords: Teacher Education; Mathematics; ENADE; Content Knowledge.

\section{Introdução}

Todas as provas de avaliação, nacionais e internacionais, sobre a Educação Básica no Brasil (Prova Brasil, PISA, ENEM, etc.) coincidem em identificar uma enorme defasagem

Submetido em: 03/11/2020 - Aceito em: 11/05/2021 - Publicado em: 17/09/2021

${ }^{1}$ Doutor em Educação pela University of Nottingham. Professor do Instituto Federal de São Paulo, campus Jundiaí Brasil. Email: leonardo.barichello@ifsp.edu.br. ORCID: https://orcid.org/0000-0001-9372-454X

2 Doutor em Matemática pela Hebrew University of Jerusalem. Professor da UNICAMP, Brasil. Email: mfirer@ime.unicamp.br. ORCID: https://orcid.org/0000-0001-6887-7683

Zetetiké, Campinas, SP, v.29, 2021, pp.1-24 - e021021 


\section{2. zêtellké}

DOI: $10.20396 /$ zet.v29i00.8661904

entre a expectativa de aprendizagem e proficiência efetivamente adquirida em todas as áreas de conhecimento. Considerando o PISA, por se tratar de um referencial externo amplamente adotado, a defasagem em matemática é significativamente maior do que em leitura ou ciências, conforme pode ser constatado na Tabela 1, onde apresentamos a média dos estudantes brasileiros e a média dos países da OCDE.

Tabela 1: Médias do Brasil e países da OCDE nas diferentes áreas avaliadas pelo PISA.

\begin{tabular}{|l|l|l|l|l|l|l|}
\hline & \multicolumn{2}{|c|}{ Leitura } & \multicolumn{2}{c|}{ Ciências } & \multicolumn{2}{c|}{ Matemática } \\
\hline & Brasil & OCDE & Brasil & OCDE & Brasil & OCDE \\
\hline PISA 2015 & 407 & 493 & 401 & 493 & 377 & 490 \\
\hline PISA 2018 & 413 & 487 & 404 & 489 & 384 & 489 \\
\hline
\end{tabular}

Considerando os resultados do PISA 2018 (Brasil, 2019), 41\% dos estudantes brasileiros foram avaliados abaixo do Nível 1 de proficiência em matemática e menos de 5\% avaliados nos níveis de proficiência 4, 5 e 6 (os níveis superiores), comparado com índices de 23,2\% (abaixo do Nível 1) e 9,3\% (níveis 4, 5 e 6) no que se refere à proficiência em leitura. O desvio padrão do PISA é de 100 pontos, o que significa que a defasagem na média em matemática do exame de 2018 (105 pontos) é superior a um desvio padrão, enquanto a defasagem em leitura (74 pontos) é bastante inferior a um desvio padrão.

Sem minimizar a relevância de fatores de natureza socioeconômica e familiar no processo educativo, estudos internacionais mostram que o conhecimento específico do professor de matemática é a variável mais relevante em termos de impacto na aprendizagem quando a análise é feita levando-se em conta variáveis relacionadas ao professor (Hill; Rowan; Ball, 2005) e, em alguns cenários, o seu impacto é muito próximo de variáveis de natureza socioeconômica (Charalambous, Hill, Chin e McGinn, 2019). Portanto, é razoável esperar que a formação dos professores, especificamente dos professores de matemática, tenha um papel relevante nos resultados aferidos na Educação Básica.

A formação inicial de professores tem sido muito discutida no Brasil por conta de esforços do poder público de propor e implementar regulamentações que tenham impacto positivo sobre a questão. Um amplo estudo sobre o tema, desenvolvido por Gatti, Sá Barreto e André (2011), aponta diversos problemas, incluindo a proliferação excessiva de cursos a distância e a estrutura de organização curricular com pouca ênfase em aspectos práticos da profissão. Segundo os autores, "a relação teoria-prática tão enfatizada em documentos e normas, com a concepção curricular integrada proposta, não se concretiza no cotidiano das diferentes licenciaturas" (Gatti et al, 2011, p. 114). A crítica posta acima se refere a cursos de licenciatura em geral, mas uma distinção é feita no que se refere aos cursos de licenciatura em matemática:

Os cursos de licenciatura em matemática diferenciam-se por apresentarem maior equilíbrio entre as disciplinas relativas aos conhecimentos específicos da área e aos conhecimentos específicos para a docência, embora as instituições públicas mantenham em sua maioria carga horária bem maior para as disciplinas relativas a 
conhecimentos específicos, espelhando mais a ideia de bacharelado do que de licenciatura. (p. 115)

As distinções apontadas por Gatti et al. (2011) entre conhecimento específico da área, conhecimento específico da docência, conhecimento teórico e prático estão relacionadas a uma grande área de pesquisa em Educação Matemática que busca compreender e caracterizar o conhecimento necessário para que professores de matemática e que ensinam matemática precisam para sua prática profissional, bem como quais são as diferentes facetas que levam a resultados de aprendizagem. Essa questão foi levantada por Shulmann (1986) para professores no geral e tem sido estudada por diversos autores em inúmeros trabalhos. No que se refere especificamente a professores de matemática, destacamos os trabalhos de um grupo de pesquisadores da Universidade de Michigan, (Ball, Thames e Phelps, 2008) e da Alemanha (Baumert et al. 2010). De modo geral, os conhecimentos necessários ao professor são diferenciados entre conhecimentos de conteúdos específicos $(\mathrm{CK})$, conhecimentos de natureza pedagógica ampla (PK) e aqueles conhecimentos de natureza pedagógica ligados aos conteúdos disciplinares $(\mathrm{PCK})^{3}$. Se há disputas sobre as possíveis formas de caracterizar e categorizar os conhecimentos e sobre o possível impacto ou utilidade destas diversas categorias, alguns consensos começam a se formar sobre alguns pontos. Em um recente prefácio de uma publicação de relevo sobre o conhecimento do professor de matemática, alguns pesquisadores ligados ao grupo de Michigan sintetizaram esses pontos da seguinte maneira:

Após várias décadas de pesquisa, nós elencamos o que vemos como um pequeno conjunto de lições que emergiram: a) Ensinar conteúdos matemáticos além de um limite básico não aumenta o conhecimento desses professores de uma maneira que causa impacto no ensino e aprendizagem; b) Criar oportunidades para que professores aprendam matemática entrelaçada com o ensino aumenta o mathematical knowledge for teaching; c) O foco no conteúdo e pedagogia para ensinar tais conteúdos requer atenção cuidadosa para que se mantenha o balanço entre conteúdo e ensino sem desviar exclusivamente para um ou para outro. (Hoover, Mosvold, Ball e Lai, 2018, p. 11-12 - tradução nossa)

A dualidade da afirmação do primeiro ponto é especialmente importante para este texto. Queremos ressaltar que se por um lado se afirma de modo explícito que conhecimentos avançados de matemática não têm impacto aparente nas ações docentes de um professor, a afirmação também coloca a existência de algum tipo de nível basal de conteúdo. Essa dualidade é salientada um pouco adiante no texto:

[...] um certo nível de conhecimento do conteúdo é essencial, mas exigir de professores ao longo da sua formação cursos que não estejam diretamente ligados ao conteúdo que ele vai ensinar ou a ações envolvidas no ensino destes conteúdos é um erro. (Hoover et al., 2018, p. 12 - tradução nossa)

\footnotetext{
${ }^{3}$ Content Knowledge (CK), Pedagogical Knowledge (PC) e Pedagogical Content Knowledge (PCK), conforme são conhecidos os termos em inglês.
} 
De fato, esta afirmação de Hoover se alinha com a conclusão de Begle (1972), que encontrou correlação significativa entre o desempenho de alunos do Ensino Básico e o conhecimentos dos professores em álgebra básica dos números reais, mas não com seus conhecimentos de álgebra moderna (grupos, anéis e corpos).

A afirmação também é coerente com Baumert et al. (2010). Os autores analisaram o impacto conhecimento do professor de matemática na aprendizagem dos seus estudantes levando em conta duas dimensões, o conhecimento de conteúdo e o conhecimento pedagógico de conteúdo. Um olhar atento às questões que foram utilizadas no instrumento de pesquisa revela que o conteúdo almejado pela primeira dimensão é estritamente ligado ao conteúdo tipicamente ensinado no Ensino Médio e não a conteúdos tipicamente ensinados em cursos de matemática do Ensino Superior.

A partir dessas constatações e considerando a composição das questões presentes no ENADE, Exame Nacional de Desempenho de Estudantes, aplicado a concluintes dos cursos de licenciatura em matemática em todo o Brasil, este trabalho pretende analisar o conhecimento de futuros professores de matemática sobre conteúdos que fazem parte do currículo da Educação Básica.

\section{Objetivos}

A pergunta que norteia este trabalho pode ser colocada como: Quanto os futuros professores de matemática dominam os conteúdos matemáticos que se espera que seus alunos dominem?

Esta pergunta demanda alguns esclarecimentos. Por "conteúdos matemáticos que se espera que seus alunos dominem" entendemos aqueles conteúdos matemáticos que se tornaram consensuais na prática escolar no Brasil, seja por via dos livros didáticos aprovados pelo Plano Nacional do Livro Didático (PNLD), pelo Exame Nacional do Ensino Médio (ENEM), pela Base Nacional Curricular Comum (BNCC) ou pela própria organização do ENADE. Em outras palavras, não entramos aqui na discussão sobre a relevância ou não desses conteúdos e dos diversos significados possíveis sobre ensino e aprendizagem, mas adotamos uma postura pragmática de estudar o que é adotado, de fato ou de direito, como conteúdos matemáticos escolares da Educação Básica.

Coerentemente, adotamos a mesma postura pragmática no que se refere a aferir o domínio de tais conteúdos por parte de professores de matemática: aceitamos, embora cientes das limitações apontadas por autores como Primi, Silva e Bartholomeu (2018) no que se refere a adequação do ENADE como instrumento de avaliação de instituições de Ensino Superior, que as expectativas de conhecimento são aquelas avaliadas em exames normalizados e normativos.

Isto posto, para tentarmos responder à pergunta colocada acima, utilizaremos os 
microdados do ENADE 2017, uma fonte de dados que inclui todos os 10.861 possíveis formandos de 2017 em todos os cursos de licenciatura em matemática do Brasil. Assim, podemos refinar nossa pergunta em torno de um objetivo mais específico: compreender qualitativamente o significado dos conceitos atribuídos a cursos de licenciatura em matemática no ENADE 2017 em termos das porcentagens de acerto das questões objetivas de conhecimento específico que compõem esta avaliação, com ênfase em questões que abordam conteúdos do Ensino Básico conforme classificação feita pela organização do ENADE. Mais adiante, mostraremos que esta classificação se coaduna com as expectativas de aprendizagem do Ensino Médio sob o ponto de vista tanto do Ministério da Educação quanto de professores de matemática.

Antes de apresentarmos os procedimentos metodológicos adotados, apresentamos brevemente a estrutura do ENADE e fazemos uma breve revisão de estudos realizados utilizando estes dados.

\section{O ENADE}

O Sistema Nacional de Avaliação do Ensino Superior (SINAES) foi instituído no Ministério da Educação (MEC) em 2004, por meio da Lei 10.8611, com o objetivo de assegurar um processo nacional de avaliação das instituições de educação superior (IES), dos cursos de graduação e do desempenho acadêmico de seus estudantes. O desempenho dos estudantes é avaliado por meio do Exame Nacional de Desempenho dos Estudantes ENADE, que substituiu o Exame nacional de Cursos, aplicado entre 1996 e 2003.

No Artigo $5^{\mathrm{a}}$, parágrafo $1^{\mathrm{o}}$, da lei de criação do SINAES, ficou estabelecido que o ENADE deve aferir o desempenho dos estudantes em relação aos conteúdos programáticos previstos nas diretrizes curriculares dos respectivos cursos de graduação, além de habilidades para se ajustar às exigências decorrentes da evolução do conhecimento e competências para compreender temas exteriores ao âmbito da profissão. O ENADE tem como objetivo exclusivo a avaliação dos cursos e instituições (os resultados individuais não são públicos) e foi instituído com o intuito de orientar as IES sobre sua eficácia acadêmica e subsidiar órgãos governamentais na formulação de políticas públicas.

Cada curso tem sido avaliado pelo ENADE a cada três anos e participam os ingressantes e concluintes do curso, onde por concluintes, no caso dos cursos de licenciatura, são considerados os estudantes que no período em questão já tenham concluído mais de $80 \%$ da carga horária do curso. As provas do ENADE contêm uma parte de formação geral comum a todos os cursos (correspondente a $1 / 4$ das questões da prova e do conceito final) e uma parte de conteúdos específicos do curso (correspondente a $3 / 4$ das questões da prova e do conceito).

O Instituto Nacional de Estudos e Pesquisas Educacionais Anísio Teixeira (INEP), 


\section{Zeterké}

DOI: $10.20396 /$ zet.v29i00.8661904

autarquia do MEC responsável pelo SINAES, disponibiliza online uma fartura de dados bem organizados sobre o ENADE no formato de microdados. Uma revisão sistemática da literatura feita por Lima, Ambrosio, Ferreira e Brancher (2019) compilou 39 trabalhos acadêmicos versando sobre o ENADE tornados públicos até 2016, agrupando-os em 6 categorias. A categorização proposta pelos autores não foi informativa em termos da questão estudada neste trabalho, mas tomamos estas referências como ponto de partida para entender o que já foi estudado sobre e a partir dos microdados do ENADE.

Esses trabalhos têm vertentes variadas. Diversos estudos tentam relacionar desempenho dos estudantes com variáveis socioeconômicas ou estrutura dos cursos e corpo docente (ver por exemplo Moriconi e Nascimento 2011, Silva e Vendramin 2010). Outros trabalhos analisam as provas considerando a grade de conteúdos e habilidades prescritas no edital do exame ou em documentos normativos de cursos (ver Costa e Martins, 2014 sobre matrizes de conteúdo de física). Outros estudos estudam os impactos e influências do ENADE na organização e currículo de cursos específicos (ver Gontijo, 2014 para cursos de pedagogia).

Nesse sentido, nenhum dos estudos identificados por Lima et al. (2019) abordaram questões que dialoguem de maneira explícita com a pergunta que colocamos neste texto. Entretanto, identificamos dois estudos que estabelecem uma relação um pouco mais próxima do que pretendemos neste artigo, e que não constam da revisão mencionada.

Rothen e Nasciutti (2011) compararam o desempenho de ingressantes e concluintes nas provas do ENADE nos anos de 2005 e 2006. São apresentados dados sobre os cursos de Arquitetura e Urbanismo, Biomedicina, Ciências Contábeis, Computação, Engenharia, Física e Formação de Professores. Os dados são apresentados de acordo com as diversas partes constitutivas da prova. Nas questões objetivas da parte específica da prova, é constatado um aumento médio de $20 \%$ (em relação ao desempenho dos ingressantes) na média das notas nos sete cursos estudados. Considerando que as questões específicas devem avaliar os conhecimentos adquiridos durante a formação profissional, esta variação é preocupantemente pequena e chama a atenção para algum problema sério na formação oferecida nas IES, na metodologia do ENADE ou em ambos. Ao estabelecerem um paralelo entre o desempenho de ingressantes e concluintes, Rothen e Nasciutti (2011) se aproximam do nosso objetivo de qualificar o conhecimento de formandos de um curso específico. Entretanto, os autores não aprofundam a discussão deste aspecto, se limitando a apresentar dados descritivos que sugerem que alguns cursos superiores estão agregando pouco conhecimento específico aos seus estudantes.

Barros, Campos, Teixeira e Cabral (2020) também se aproximam dos nossos objetivos ao analisarem o desempenho de estudantes de Educação Física no ENADE 2014 em termos do conteúdo abordado em parte das questões. Dessa forma, os autores vão além da apresentação dos índices de acerto e sugerem o que estes podem significar, de um ponto de vista qualitativo, em termos dos conhecimentos esperados e das práticas desses profissionais. 
Barros et al. (2020) mencionam o baixo desempenho no componente de formação específica, que teve média de acertos de 46,2\% e argumentam, a partir de uma análise do conteúdo dessas questões, que tal resultado sugere deficiências graves em termos da futura prática profissional desses estudantes.

Nosso estudo pretende abordar de maneira mais explícita essa questão no que se refere a licenciaturas em matemática: o que é possível inferir, para além dos conceitos atribuídos às instituições, a partir dos dados do ENADE acerca do conhecimento matemático de futuros professores de matemática?

\section{Tratamento dos dados}

A prova do ENADE é composta por dez questões de formação geral, sendo duas discursivas e oito objetivas, trinta questões de formação específica, sendo três discursivas e vinte e sete objetivas e, ao final, um questionário de percepção da prova (com nove questões de múltipla escolha). Além disto, há um questionário sócio econômico e de percepção do estudante sobre o seu curso. No caso da licenciatura em matemática, há também um questionário com treze itens específicos sobre o curso. Estes questionários devem ser preenchidos online, de antemão, pelos estudantes.

Em princípio, tanto ingressantes quanto concluintes devem se cadastrar para participação na prova, porém, após os primeiros anos de implementação do ENADE, os ingressantes têm sido dispensados. Nos microdados que utilizamos para este texto não há nenhum campo que sugira essa distinção entre os sujeitos e a distribuição da variável "ano de ingresso" indica que os dados contêm apenas informações sobre concluintes ${ }^{4}$.

O cálculo do conceito ENADE de um curso

O procedimento detalhado para o cálculo do conceito ENADE de um curso pode ser consultado em Brasil (2017). Em síntese, esse cálculo é feito da seguinte maneira, considerando-se como universo os cursos participantes de uma área determinada (por exemplo, todos os cursos de licenciatura em matemática):

a) toma-se a média ponderada entre a nota bruta nas questões de formação geral (25\%) e as questões de conhecimentos específicos $(75 \%)$ de todos os estudantes do curso de uma determinada IES;

b) essa média é normalizada para a escala padrão em relação a todos os cursos e IESs participantes;

\footnotetext{
${ }^{4}$ Nos dados do ENADE 2017, dentre os alunos dos cursos de licenciatura em matemática havia apenas dois com ano de ingresso em 2017, possivelmente alunos que reingressaram para concluir poucas matérias faltantes em seu currículo.
} 
c) o intervalo entre a menor e a maior média é convertido para uma escala de 0 a 5 e, finalmente;

d) este intervalo é dividido em 5 intervalos de mesma amplitude de modo que as notas em cada um deles sejam convertidas nos conceitos de 1 a 5 .

Exemplificaremos a sistemática de cálculo de conceito do ENADE, utilizando os dados referentes aos 426 cursos de licenciatura em matemática avaliados em 2017. O gráfico na Figura 1 mostra a distribuição de notas após o passo (c) e antes do passo (d) descrito acima.

O gráfico mostra que as notas se comportam de maneira próxima a uma distribuição normal (média igual a 2,20 e desvio padrão igual a 0,88). Comportamento semelhante é observado se considerarmos o conceito ENADE obtido depois da etapa (d), que arredonda para cima os valores agrupando-os em 5 conceitos.

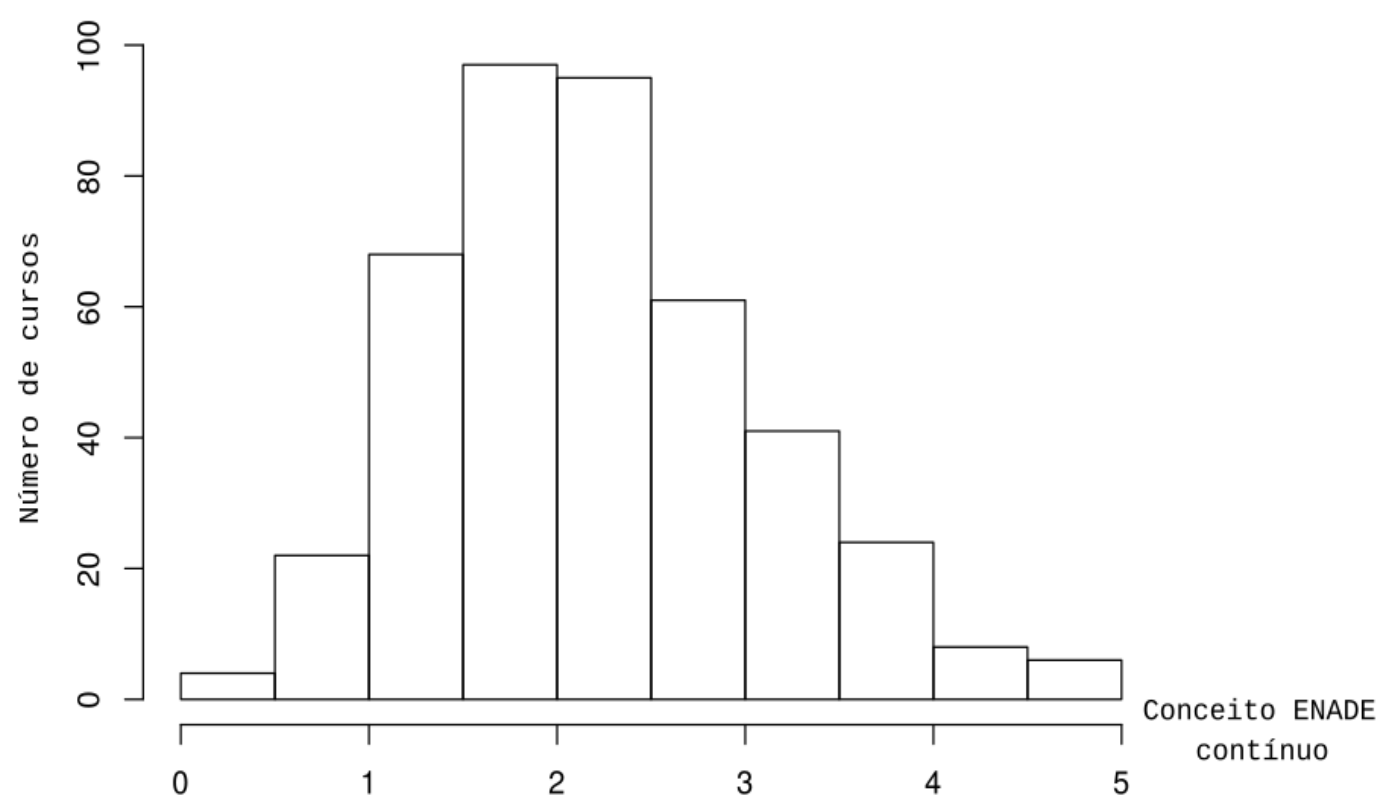

Figura 1: Histograma do conceito ENADE contínuo dos cursos de licenciatura em matemática Fonte: Elaboração dos autores com base nos dados do ENADE 2017

A distribuição dos cursos, entre os conceitos, muda quando consideramos, ao invés da quantidade de cursos, a quantidade de alunos nestes cursos. 
DOI: 10.20396/zet.v29i00.8661904

Tabela 2: Concentração de estudantes por cursos

\begin{tabular}{|l|l|l|l|l|l|}
\hline Conceito & $\begin{array}{c}\text { Número } \\
\text { de cursos }\end{array}$ & $\begin{array}{c}\text { Total de } \\
\text { estudantes }\end{array}$ & $\begin{array}{c}\text { Porcentagem } \\
\text { acumulada de } \\
\text { cursos }\end{array}$ & $\begin{array}{c}\text { Porcentagem acumulada } \\
\text { de estudantes nos cursos }\end{array}$ & $\begin{array}{c}\text { Número médio de } \\
\text { estudantes por curso }\end{array}$ \\
\hline 1 & 22 & 412 & $5 \%$ & $3,79 \%$ & 18,73 \\
\hline 2 & 160 & 5618 & $43 \%$ & $55,42 \%$ & 35,11 \\
\hline 3 & 158 & 3506 & $80 \%$ & $87,64 \%$ & 22,19 \\
\hline 4 & 71 & 1133 & $96 \%$ & $98,05 \%$ & 15,96 \\
\hline 5 & 15 & 212 & $100 \%$ & $100 \%$ & 14,13 \\
\hline
\end{tabular}

Fonte: Elaboração dos autores com base nos dados do ENADE 2017

Na Tabela 2 vemos que os cursos com conceito 2 são aqueles que concentram maior quantidade de estudantes. Essa diferença na concentração de estudantes faz com que haja muitos estudantes em cursos com os conceitos mais baixos no ENADE. Conforme veremos mais adiante, se considerarmos os alunos de todos os cursos que tem desempenho individual equivalente ao dos cursos avaliados com conceito 1 ou 2 , esta proporção crescerá ainda mais.

A pergunta que motivou este trabalho refere-se ao conhecimento matemático de professores de matemática, e não aos cursos de formação de professores. Assim, para tentar responder a esta pergunta utilizando os dados do ENADE, optou-se por utilizar o critério utilizado pelo INEP para definir os conceitos dos cursos para definir o conceito ENADE do participante, que explicamos a seguir.

\section{O cálculo do conceito ENADE de um estudante}

Para determinar o conceito ENADE dos licenciandos em matemática, adotou-se um procedimento muito próximo ao utilizado pelo INEP para o cálculo de conceito de cursos (descrito na sessão anterior) para obter um conceito ENADE individual para cada estudante ${ }^{5}$. Os passos adotados são os seguintes:

- consideramos a média ponderada entre a nota bruta nas questões de formação geral (25\%) e as questões de conhecimentos específicos (75\%) para cada um dos estudantes de licenciatura em matemática que fizeram o ENADE. Nesta etapa, o INEP considera as notas dos estudantes de cada curso;

- essa média foi convertida para a escala padrão em relação à média e desvio padrão desse grupo, considerando os 10.861 estudantes como universo (ao invés dos cursos, conforme feito pelo INEP);

\footnotetext{
${ }^{5}$ Reconhecemos aqui uma limitação intrínseca a esta abordagem, pois sendo o ENADE um exame feito com o objetivo de avaliar os cursos, sem consequências significativas aos egressos, o empenho dos estudantes ao fazer esta prova pode ser questionável. Não obstante, esta é uma limitação intrínseca ao ENADE, que é o único exame em escala feito com concluintes de cursos de graduação.
} 
- o intervalo entre a menor e a maior média é convertido para uma escala de 0 a 5. Entretanto, neste passo, ao invés de utilizarmos os valores mínimos e máximos dos estudantes, decidimos utilizar os mesmos que foram utilizados pelo INEP no cálculo do conceito de cada curso. Dessa forma, a analogia entre os conceitos dos cursos e dos participantes é mais direta $^{6}$. Observamos que a nota mínima de cursos e indivíduos é a mesma (zero) mas o máximo das médias dos cursos é ligeiramente menor que a dos indivíduos;

- O quarto passo converte a nota contínua individual em conceitos discretos de 1 a 5 .

Dessa forma, obtemos uma nota para cada estudante que pode ser interpretada de maneira análoga à nota atribuída aos cursos pelo INEP.

\section{Extração e processamento dos dados}

As duas fontes de dados utilizadas neste texto são o relatório de conceitos do ENADE 2017 e os microdados do ENADE 2017 disponibilizados pelo INEP. Ambas disponíveis no site do INEP. Os demais arquivos referidos na descrição abaixo estão disponíveis em https://osf.io/qpt8c/.

O primeiro deles traz os conceitos de todos os cursos avaliados no ENADE 2017 (último a avaliar cursos de licenciatura em matemática) de cada IES brasileira. A partir deste arquivo, geramos (via software de planilha eletrônica) um novo conjunto de dados com todos os cursos de licenciatura em matemática constantes no documento, sua nota bruta em formação geral e em formação específica, sua nota padronizada em formação geral e em formação específica, sua nota ENADE contínua, seu conceito ENADE e o código da IES.

O processamento realizado nos microdados foi mais trabalhoso. Devido ao nosso objetivo de compreender qualitativamente o significado de cada conceito em funções dos índices de acerto em cada uma das 27 questões objetivas que contidas na prova específica. Essas informações são apresentadas nos microdados em três formatos: um vetor com as alternativas assinaladas pelo respondente para cada uma das 27 questões, um vetor com as alternativas corretas de cada questão e um vetor formado por 0's e 1's indicando erro ou acerto para cada uma das questões. Para poder acessar o índice de acertos de cada questão, foi utilizado um script escrito em linguagem $\mathrm{C}$ que lê os microdados, copia os campos de interesse dos pesquisadores e separa o vetor de acertos em 27 campos independentes, facilitando a análise posterior. O resultado deste processo é um novo conjunto de dados contendo apenas os participantes que estavam cursando licenciatura em matemática e que

\footnotetext{
${ }^{6}$ Por conta disso, houve um número muito pequeno $(n=5)$ de estudantes com conceito superior a 5 por terem nota maior do que a maior nota de uma instituição. Por simplicidade, esses estudantes foram tratados como tendo obtido conceito 5 .
} 
tiveram presença regular na aplicação do exame $(n=10.861)$ com o vetor de acertos separado em campos independentes.

Uma vez realizadas essas etapas, os dois novos conjuntos de dados foram importados no software R para uma rodada final de processamento. Dessa maneira, uma nova tabela com a frequência de acerto de cada questão para os estudantes que foram agrupados em cada um dos 5 conceitos do ENADE foi gerada. Essa tabela é a referência básica para a discussão que faremos na próxima seção e pode ser replicada a partir dos documentos oficiais disponíveis no site do INEP, do script em $\mathrm{C}$ e dos comandos em $\mathrm{R}$ disponíveis em https://osf.io/qpt8c/ com a tabela propriamente dita.

\section{Análise de dados}

Nesta seção apresentaremos algumas informações descritivas e faremos a análise dos dados gerados a partir dos microdados do ENADE visando responder à pergunta proposta.

\section{Distribuição de estudantes por conceito ENADE}

Primeiramente, vejamos abaixo a concentração de estudantes por conceito. Note que essa distribuição é diferente da mostrada na Figura 1. De certa forma, isso já era esperado ao considerarmos a concentração de estudantes em cursos com conceito ENADE 2 e 3 mostrada na Tabela 2.

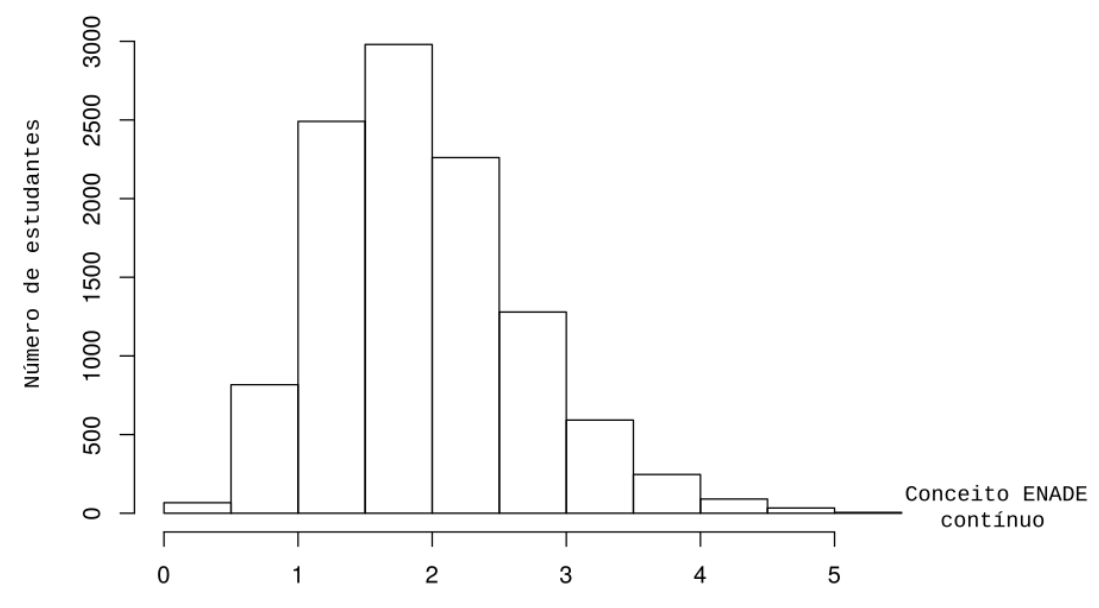

Figura 2: Histograma dos conceitos ENADE contínuo para estudantes Fonte: Elaboração dos autores com base nos dados do ENADE 2017

O gráfico de barras abaixo mostra a frequência de cada conceito, uma vez feito o arredondamento usado no cálculo do conceito ENADE de um curso. 


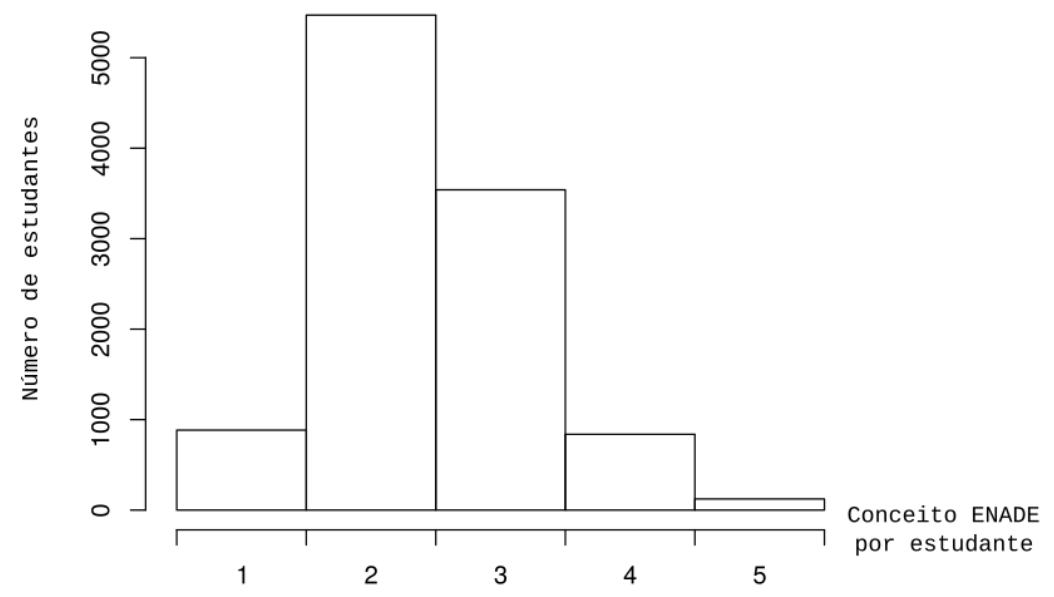

Figura 3: Número de estudantes por conceito ENADE.

Fonte: Elaboração dos autores com base nos dados do ENADE 2017

Observa-se que o histograma se comporta de maneira próxima a uma curva normal (média igual a 1,93 e desvio padrão igual a 0,75 ) com média menor do que o histograma da Figura 1. O gráfico da Figura 3 mostra a frequência de cada conceito, uma vez feito o arredondamento usado no cálculo do conceito ENADE de um curso. Além disso, este gráfico está ainda mais concentrado no conceito 2 do que o mostrado na Figura 1, como resultado da maior concentração de estudantes em instituições com conceitos baixos no ENADE. Na tabela abaixo podemos comparar o número de alunos em cursos com dado conceito (conforme aparece na Tabela 2, dados calculados diretamente pelo INEP) e o número de alunos que, como indivíduos, obteriam o conceito dado. Este último dado é o que calculamos acima.

Tabela 3: Comparação entre a concentração de cursos e estudantes em cada conceito.

\begin{tabular}{|l|r|r|r|r|}
\hline Conceito & $\begin{array}{c}\text { Porcentagem de } \\
\text { alunos em cursos } \\
\text { com conceito dado }\end{array}$ & $\begin{array}{c}\text { Porcentagem } \\
\text { acumulada de } \\
\text { alunos nestes cursos }\end{array}$ & $\begin{array}{c}\text { Porcentagem de } \\
\text { alunos com conceito } \\
\text { dado }\end{array}$ & $\begin{array}{c}\text { Porcentagem } \\
\text { acumulada de alunos } \\
\text { com conceito dado }\end{array}$ \\
\hline 1 & $3,79 \%$ & $3,79 \%$ & $5,99 \%$ & $5,99 \%$ \\
\hline 3 & $51,63 \%$ & $55,42 \%$ & $52,32 \%$ & $58,31 \%$ \\
\hline 4 & $32,22 \%$ & $87,64 \%$ & $34,86 \%$ & $93,17 \%$ \\
\hline 5 & $10,41 \%$ & $98,05 \%$ & $6,31 \%$ & $99,48 \%$ \\
\hline
\end{tabular}

Fonte: Elaboração dos autores com base nos dados do ENADE 2017

Devemos observar que, olhando para os indivíduos, a concentração aumenta nos conceitos mais baixos e os melhores conceitos diminuem significativamente: o número de estudantes com conceito 5 é cerca de $1 / 4$ do número de estudantes em cursos com conceito 5 .

Até este ponto, foi feito um tratamento estatístico, calculando e comparando o conceito ENADE por estudante, o que nos parece mais significativo do que o conceito ENADE de cursos se quisermos inferir algo sobre o conhecimento matemático dos 
DOI: 10.20396/zet.v29i00.8661904

professores recém formados. Na próxima sessão, entraremos no mérito da questão proposta neste texto, buscando significados tangíveis para cada um dos conceitos, agregando aos dados estatísticos uma análise dos conteúdos matemáticos das questões objetivas da parte específica da prova do ENADE 2017.

\section{Uma possível interpretação para o significado de cada conceito}

Avaliações de larga escala como o ENADE servem para estabelecer um parâmetro de comparação entre instituições, seja para a tomada de decisões públicas quanto para informar a sociedade como um todo acerca da qualidade dos serviços prestados ou ofertados pelas diferentes IES. Entretanto, por não utilizar metodologias como a TRI, o ENADE não permite análises ao longo do tempo, seja para cursos específicos (esse curso melhorou em relação à última avaliação?) ou para o conjunto (os cursos de licenciatura em matemática do Brasil estão melhorando ao longo dos anos?).

Por ser um exame com resultados padronizados, para se apreender algo o que significa um curso ter obtido um determinado conceito no ENADE em termos daquilo que seus estudantes demonstram saber, uma opção é fazer uma análise qualitativa dos conteúdos abordados.

Como dito anteriormente, o ENADE é composto por dois conjuntos de questões, as de conhecimento geral, que versam sobre interpretação de textos e resolução de problemas não específicos as áreas do conhecimento, e as de conhecimento específico, que são desenvolvidas especificamente para cada curso considerando as Diretrizes Curriculares Nacionais dos cursos de graduação, o Catálogo Nacional de Cursos Superiores de Tecnologia e outros documentos oficiais relevantes (BRASIL, 2017. Neste texto focaremos nossa análise nas questões objetivas de conhecimento específico.

Para a licenciatura em matemática, estas questões são criadas pelo INEP em dois grandes grupos, o primeiro com as questões de matemática (18, no total), que também figuram na avaliação dos cursos de bacharelado em matemática, e as de natureza pedagógica ou pedagógica de conteúdos (9, no total), que figuram apenas na prova da licenciatura em matemática (BRASIL, 2017).

Uma inspeção do primeiro grupo de questões permite notar uma segunda distinção pertinente para os objetivos deste texto: questões cujo conteúdo necessário para resolução são abordados ao longo da Educação Básica e questões que demandam conhecimentos tipicamente abordados no Ensino Superior.

Como discutido anteriormente, embora possa haver discussões sobre quais conteúdos estão além do limiar a partir da qual o domínio, por parte do professor, não gera resultados de aprendizagem, é consensual que o professor deve ao menos saber aquilo que vai ensinar (Lorenzato, 2006; Hoover et al, 2016). Nesse sentido, nos parece pertinente analisar o 
DOI: $10.20396 /$ zet.v29i00.8661904

conhecimento dos futuros professores de matemática avaliados no ENADE em termos do desempenho nas questões que demandam apenas conteúdos matemáticos da Educação Básica.

\section{Questões matemáticas da Educação Básica e de Ensino Superior}

O INEP remove questões do cálculo do conceito ENADE quando estas atingem ponto bisserial abaixo de 0,2 (BRASIL, 2017). Nesses casos, os dados sobre acerto são omitidos dos microdados, o que nos forçou a não considerá-las na nossa análise. Em 2017, isso ocorreu com 4 questões (todas de conteúdo matemático), o que nos deixou com 9 questões de caráter pedagógico $(\mathrm{PE})$ e 14 sobre conteúdos matemáticos.

No Anexo IXb (BRASIL, 2017), o INEP reporta os elementos que caracterizam cada uma das questões utilizadas na prova, sendo eles: características do perfil profissional, competências e conteúdos curriculares. Para o elemento conteúdos curriculares, uma das categorias presentes é "conteúdos matemáticos da Educação Básica". Dentre as questões presentes na edição 2017 que foram classificadas nesta categoria ( 8 no total), uma foi anulada e outra está no grupo de questões de conteúdo pedagógico, que fogem do escopo deste artigo.

Em termos dos modelos de conhecimento do professor de matemática mencionados na introdução, as seis questões restantes se alinham às questões utilizadas em Baumert et al (2010) para avaliar ocomponente chamado de content knowledge e ao que Ball et al (2008) chamam de common content knowledge, ou seja, aquele conhecimento que poderia ser utilizado em outros contextos diferentes do educacional, sendo portanto não específico ao professor de matemática. Embora os autores dos dois trabalhos admitam que conhecimentos desta natureza não parecem ser aqueles com maior impacto na aprendizagem dos estudantes, ambos admitem que ele faz parte do arsenal de conhecimentos necessários para a prática docente.

Sabendo que o corpo de profissionais que atua no INEP são vinculados ao Ensino Superior e não necessariamente à Educação Básica, os autores acharam pertinente verificar pragmaticamente esta classificação submetendo-a a apreciação de professores de Matemática em exercício na Educação Básica. Dessa forma, estaríamos reforçando a característica principal que buscamos nessas questões: refletirem o conteúdo que se espera que estudantes dominem ao final da sua escolarização.

Para tanto, convidamos 11 professores de matemática com pelo menos 2 anos de experiência no Ensino Médio para classificarem as questões com base exclusivamente no conteúdo requerido para a resolução, e não na sua dificuldade, em duas categorias: Educação Básica e Ensino Superior. A amostra de professores participantes foi feita por proximidade, sem a intenção de torná-la representativa, já que entendemos que o currículo matemático da Educação Básica é amplamente conhecido e bastante homogêneo no Brasil. Vale salientar que 
os participantes não estavam cientes do teor do estudo a ponto de que isso pudesse influenciar as suas respostas. A classificação foi feita com auxílio de formulário online e os resultados são mostrados na tabela 4 .

Tabela 4: Classificação das questões categorizadas como “conteúdos matemáticos da Educação Básica” feita por professores de matemática.

\begin{tabular}{|l|r|r|r|r|r|r|}
\hline & Questão 10 & Questão 15 & Questão 17 & Questão 18 & Questão 22 & Questão 24 \\
\hline Ensino Superior & 2 & 1 & 0 & 0 & 0 & 3 \\
\hline Educação Básica & 9 & 10 & 11 & 11 & 11 & 8 \\
\hline
\end{tabular}

Fonte: própria

Como pode ser visto na tabela, houve um bom grau de concordância entre a classificação realizada pelos professores de matemática em atividade e a categorização reportada no relatório do INEP. Como o objetivo deste artigo não é problematizar essa categorização das questões, apenas confirmar pragmaticamente que o conteúdo abordado em algumas questões do ENADE 2017 para licenciatura em matemática é compatível com o conteúdo que se espera que seja ensinado para estudantes da Educação Básica, não nos preocupamos com a significância estatística da análise apresentada, uma vez que três elementos distintos parecem convergir sobre essa categorização: as informações reportadas pelo INEP, a classificação por professores de matemática em atividade e a percepção qualificada dos autores.

Assim, para realização da análise apresentada a seguir, foram consideradas 6 questões $(10,15,17,18,22$ e 24, seguindo a numeração da prova do ENADE) como sendo questões envolvendo conteúdos da Educação Básica (EB). As demais foram consideradas como envolvendo conteúdos do Ensino Superior (ES) e estão inclusas na tabela a seguir, juntamente com as questões de caráter pedagógico (PE), apenas para fins informativos.

O desempenho dos estudantes nos diferentes tipos de questão

A tabela a seguir mostra a porcentagem de acerto entre estudantes que obtiveram cada um dos cinco conceitos.

Tabela 5: Índice de acerto das questões de cada tipo: Questões de caráter pedagógico (PE), questões sobre conteúdo matemático da Educação Básica (EB) e Ensino Superior (ES)

\begin{tabular}{|l|l|l|l|}
\hline & Questões EB & Questões ES & \multicolumn{1}{|c|}{ Questões PE } \\
\hline Conceito 1 & $13,0 \%$ & $12,6 \%$ & $16,1 \%$ \\
\hline Conceito 2 & $22,0 \%$ & $25,1 \%$ & $33,4 \%$ \\
\hline Conceito 3 & $36,0 \%$ & $40,3 \%$ & $56,0 \%$ \\
\hline Conceito 4 & $61,2 \%$ & $65,6 \%$ & $72,8 \%$ \\
\hline Conceito 5 & $86,6 \%$ & $88,4 \%$ & $86,7 \%$ \\
\hline
\end{tabular}

Fonte: própria 
DOI: 10.20396/zet.v29i00.8661904

É importante salientar que essas são as questões objetivas, no formato de múltipla escolha com 5 alternativas. Nesse sentido, chama a atenção o fato de que os estudantes com conceito 2 terem demonstrado nessa avaliação uma frequência de acerto pouco acima do índice de $20 \%$ (valor esperado no caso de respostas aleatórias) nas questões do tipo EB. Esse cenário é preocupante, uma vez que esses futuros professores serão habilitados a atuar no Ensino Médio e 58,31\% dos licenciandos em matemática que participaram do ENADE 2017 teriam conceito 1 ou 2 e 93,17\% conceito até 3, como mostrado na Tabela 23.

Considerando o nosso objetivo de compreender o significado de cada conceito ENADE em termos do conhecimento matemático de futuros professores de matemática no Brasil, elegemos 2 questões para análise mais detalhada, as questões 15 e 20. Elas foram escolhidas pela grande similaridade com outras duas questões que apareceram em edições recentes do ENEM (vide Anexo 2). Esta similaridade com o ENEM reforça a representatividade das questões 15 e 20 para abordarmos a questão que norteia este trabalho: espera-se que alunos do Ensino Médio sejam capazes de resolvê-las corretamente.

A identificação dessas duas questões foi fortuita, tendo surgido da familiaridade do primeiro autor com essas duas avaliações. Embora as matrizes de avaliação do ENADE e ENEM, bem como seus objetivos e consequências para os participantes, sejam diferentes, a similaridade entre as questões mencionadas é saliente tanto quando se analisa os enunciados, comandos e alternativas que compõem cada uma delas como quando se considera as soluções plausíveis. Vale salientar, que o fato de haver tamanha similaridade entre questões de dois exames que são aplicados a estudantes de níveis de ensino distintos não é surpreendente, uma vez que o domínio do conteúdo a ser ensinado é uma das dimensões do conhecimento específico que se espera de um professor de matemática (SHULMANN, 1986; BALL et al, 2008; BAUMERT et al, 2010; HOOVER et al, 2016). Traduzindo de forma muito simples: "ninguém consegue ensinar o que não sabe" (Lorenzato, 2006, p.3).

O primeiro par, formado pela questão 15 do ENADE 2017 e pela questão 155 da prova cinza do ENEM 2009, versa sobre o conceito de função e pede que seja obtida a expressão algébrica de uma função quadrática que modela uma situação descrita no contexto de vendas. O segundo par, formado pela questão 20 do ENADE 2017 e pela questão 138 da prova cinza do ENEM 2017, pede o cálculo da probabilidade de um evento composto por uma série de eventos independentes relacionados à previsão do tempo.

O índice de acerto geral dessas duas questões do ENADE foi de 22,7\% e 20,3\% respectivamente, números em sí bastante preocupantes. Entretanto, podemos também olhar esse índice de acerto entre os estudantes em cada conceito, como mostrado a seguir. 
DOI: 10.20396/zet.v29i00.8661904

Tabela 6: Índice de acerto das duas questões selecionadas por conceito

\begin{tabular}{|l|l|l|}
\hline & \multicolumn{1}{|c|}{ Questão 15 } & \multicolumn{1}{c|}{ Questão 20 } \\
\hline Conceito 1 & $12,4 \%$ & $11,4 \%$ \\
\hline Conceito 2 & $18,5 \%$ & $18,4 \%$ \\
\hline Conceito 3 & $31,8 \%$ & $25,4 \%$ \\
\hline Conceito 4 & $58,7 \%$ & $59,4 \%$ \\
\hline Conceito 5 & $91,1 \%$ & $91,1 \%$ \\
\hline
\end{tabular}

Fonte: própria

Esses dados tornam o problema já salientado acima ainda mais explícito. No caso dessas duas questões que, repetimos, são muito similares a questões cobradas em edições recentes do ENEM, o índice de acerto dos estudantes que obtiveram conceito 2 é abaixo de $20 \%^{7}$. Não apenas isso, mas o índice observado entre os estudantes de conceito 3 é pouco superior a essa porcentagem, o que no mínimo levanta incertezas sobre a proficiência adquirida por futuros professores na maioria dos cursos de licenciatura em matemática do Brasil e, preocupação que deve ser estendida a qualidade dos cursos em questão. Vale salientar que o ENEM é um exame que é feito pela maioria dos estudantes brasileiros que completam o Ensino Médio e que se estabeleceu como referência quase única para a seleção de estudantes para o Ensino Superior. Nesse sentido, usá-lo como referência para aquilo que estudantes deste nível de ensino devem aprender nos parece razoável.

Como professores de matemática, tampouco vemos motivos objetivos para considerar que essas duas questões sejam especialmente desafiadoras, o que poderia explicar os índices de acerto apresenta na Tabela 6. A primeira delas pede apenas a expressão algébrica de uma função quadrática, um dos tipos de função mais trabalhados ao longo do Ensino Médio, e o contexto (envolvendo vendas e desconto) é frequentemente utilizado desde o Ensino Fundamental. A segunda questão, faz uso um contexto comum em questões de probabilidade, não utiliza nenhum artifício que induza ao erro ou estratégia de resolução que possa ser considerada inusitada. Portanto, ambas podem ser consideradas bons representantes do tipo de conhecimento matemático que se espera de estudantes dos últimos anos do Ensino Médio e, consequentemente, de seus professores.

\section{Conclusões}

O objetivo que norteou este trabalho foi compreender um dos componentes usualmente apontados como fundamental, embora não único, para a prática de futuros professores de matemática: o seu conhecimento de conteúdos específicos. O estudo foi feito a

\footnotetext{
${ }^{7}$ Os índices de acerto significativamente inferiores a $20 \%$ chamam a atenção e podemos apenas conjecturar que se devam a algum distrator presente nas questões. Não foi possível avaliar esta hipótese a partir dos dados disponíveis pois estes apenas apresentam acerto ou erro, sem indicar as alternativas assinaladas.
} 
partir dos microdados do ENADE 2017 considerando um universo de 10.861 possíveis concluintes em todo o Brasil.

Em uma primeira etapa, verificamos que se usarmos a metodologia utilizada pelo INEP para atribuir conceitos aos cursos para atribuir conceitos individuais a cada um dos participantes, 93,17\% dos possíveis formandos receberiam conceito menor ou igual a 3.

Para apreendermos algo substantivo sobre os conhecimentos destes possíveis professores, analisamos primeiramente o índice de acerto dos participantes nas questões objetivas de conteúdo matemático.

Analisamos o desempenho dos participantes em 6 questões da prova cujo conteúdo foi classificado tanto pelo INEP quanto por uma amostra de professores atuantes na educação básica e pelos dois autores como sendo compatível com a Educação Básica. Os 10.120 estudantes que obteriam conceito individual igual ou menor a 3 na edição 2017 do ENADE tiveram, em média, 27,0\% de acertos nestas questões. Salientamos que estas são questões de múltipla escolha com 5 alternativas, ou seja, respostas aleatórias teriam uma média de $20 \%$ de acerto.

Em seguida, destacamos o índice de acerto em duas dessas questões que identificamos como muito similares a duas questões de edições recentes do ENEM. Nestas questões específicas, o índice de acerto foi ainda mais baixo entre os estudantes com conceito igual ou menor a 3: $22,7 \%$ e $20,3 \%$, respectivamente. Vale salientar que essas questões foram não apenas classificadas como sendo de Ensino Médio, mas também se assemelham muito com questões que efetivamente fizeram parte de um exame direcionado a estudantes do Ensino Médio, ou seja, cujo conteúdo seguramente faz parte do repertório que se espera ter sido desenvolvido ao final de um curso de licenciatura em matemática.

Embora os autores estejam cientes das diferenças entre o ENADE e o ENEM, em termos do formato da prova, metodologia de desenvolvimento, objetivos e matrizes, a similaridade entre as questões e os níveis de desempenho identificados tornam o paralelo traçado muito relevador no que diz respeito ao objeto de estudo deste artigo, o conhecimento de conteúdo de futuros professores de matemática.

Há na literatura internacional um grande esforço em caracterizar de maneira mais clara quais tipos de conhecimento são necessários para uma prática docente em matemática que efetivamente resulte em aprendizagem. Trabalhos como Ball et al. (2008), Baumert et al. (2010), Carrillo-Yañez et al. (2018) e Charalambous et al. (2019) estão entre os que buscam essas respostas. Apesar de pequenas divergências que eventualmente surgem devido a escolhas e ênfases específicas, os autores concordam que o professor deve saber, no mínimo, o conteúdo matemático que se espera que seus estudantes aprendam ou, simplesmente, "ninguém consegue ensinar o que não sabe" (Lorenzato, 2006, p.3). 
O que os nossos resultados apontam é que esse nível basal de conhecimento matemático, definido a partir de referências de fato desenvolvidas para os estudantes, parece não ser atingido por $93 \%$ dos licenciandos em matemática próximos de concluírem seus cursos.

Cientes que os resultados de provas normalizadas são apenas indicadores da realidade, não obstante, os resultados desta análise são deveras contundentes, e suscitam ao menos duas questões urgentes do ponto de vista de políticas públicas: como é possível mudar substancialmente e de modo efetivo a formação inicial de professores de matemática? Considerando que é inevitável que parte significativa destes formandos venha a efetivamente lecionar na Educação Básica, que suporte precisam receber para que desenvolvam o conhecimento necessário para a sua prática docente?

\section{Agradecimentos}

O presente trabalho foi realizado com apoio da Coordenação de Aperfeiçoamento de Pessoal de Nível Superior - Brasil (CAPES) - Código de Financiamento PQ 304046/2017-5.

\section{Referências}

Ball, D. L., Thames, M. H., \& Phelps, G. (2008). Content Knowledge for Teaching: What Makes It Special? Journal of Teacher Education, 59(5), 389-407. DOI: https://doi.org/10.1177/0022487108324554

Barros, J. L. C., Campos, M. Z., Teixeira, D. D. C., \& Cabral, B. G. A. T. (2020). Reflexões sobre o nível de conhecimentos específicos dos estudantes de licenciatura em Educação Fisica no Enade 2014. Revista Brasileira de Estudos Pedagógicos, 101(257), 99-119. DOI: https://doi.org/10.24109/2176-6681.rbep.101i257.4374

Baumert, J., Kunter, M., Blum, W., Brunner, M., Voss, T., Jordan, A., ... Tsai, Y.-M. (2010). Teachers' Mathematical Knowledge, Cognitive Activation in the Classroom, and Student Progress. American Educational Research Journal, 47(1), 133-180. DOI: https://doi.org/10.3102/0002831209345157

Begle, E. G. (1972) Teacher Knowledge and Student Achievement in Algebra, School Mathematics Study Group Reports Number, 9.

Brasil (2017). Instituto Nacional de Estudos e Pesquisas Educacionais Anísio Teixeira. Relatório Síntese de Área Matemática (Bacharelado/Licenciatura). Brasília. Disponível em: http://portal.inep.gov.br/educacao-superior/enade/outros-documentos.

Brasil (2019). Instituto Nacional de Estudos e Pesquisas Educacionais Anísio Teixeira. Relatório Brasil no PISA 2018 (Versão Preliminar), Brasília. Disponível em: http://download.inep.gov.br/acoes_internacionais/pisa/documentos/2019/relatorio_PISA 2018 _preliminar.pdf. 
Carrillo-Yañez, J., Climent, N., Montes, M., Contreras, L. C., Flores-Medrano, E., EscuderoÁvila, D., ... Muñoz-Catalán, M. C. (2018). The mathematics teacher's specialised knowledge (MTSK) model. Research in Mathematics Education, 20(3), 236-253. DOI: https://doi.org/10.1080/14794802.2018.1479981

Charalambous, C. Y., Hill, H. C., Chin, M. J., \& McGinn, D. (2020). Mathematical content knowledge and knowledge for teaching: Exploring their distinguishability and contribution to student learning. Journal of Mathematics Teacher Education, 23(1), 579613. DOI: https://doi.org/10.1007/s10857-019-09443-2

Costa, J. P. C., \& Martins, M. I. (2014). O ENADE para a licenciatura em física: Uma proposta de matriz de referência. Revista Brasileira de Ensino de Física, 36 (3), 697-724.

Gatti, B.A., Barreto, E. S. S., \& André, M. E. D. A. (2011). Políticas docentes no Brasil: um estado da arte. Brasília, DF: Unesco.

Gontijo, S. B. F. (2014). Implicações do ENADE para a organização do trabalho pedagógico $e$ as práticas avaliativas em um curso de Pedagogia. Tese de Doutorado em Educação. Brasília: Universidade de Brasília.

Hoover, M., Mosvold, R., Ball, D. L., \& Lai, Y. (2016). Making Progress on Mathematical Knowledge for Teaching. The Mathematics Enthusiast, 13(1), 3-34.

Leitão, T. M. S. P., Moriconi, G. M., Abrão, M., \& Silva, D. S. (2010). Análise acerca do boicote dos estudantes aos exames de avaliação do ensino superior. Estudos em Avaliação Educacional, 21(45), 87-106. https://doi.org/10.18222/eae214520102028

Lima, P. S. N., Ambrósio, A. P. L., Ferreira, D. J., \& Brancher, J. D. (2019). Análise de dados do Enade e Enem: Uma revisão sistemática da literatura. Avaliação: Revista da Avaliação da Educação Superior (Campinas), 24(1), 89-107. DOI: https://doi.org/10.1590/s1414-40772019000100006

Lorenzato, S. (2006) Para aprender matemática. Campinas: Autores Associados.

Moriconi, G. M., \& Nascimento, P. A. M. M. (2014). Fatores associados ao desempenho dos concluintes de Engenharia no Enade 2011. Revista Estudos em Avaliação Educacional, 25(57), 248-278.

Primi, R., Silva, M. C. R., \& Bartholomeu, D. (2018). A validade do ENADE para avaliação de cursos superiores: Uma abordagem multinível. Revista Examen, 2(2), 128-151.

Rothen, J. C., \& Nasciutti, F. (2011). A Educação Superior em Prova: o perfil da educação superior apresentado pelos resultados do ENADE 2005 e 2006. Revista Diálogo Educacional, 11(32), 187-206.

Silva, M. C. R., Vendramini, C. M. M., \& Lopes, F. L. (2010). Diferenças entre gênero e perfil sócio-econômico no Exame Nacional de Desempenho do Estudante. Avaliação, Campinas e Sorocaba, 15(3), 185-202. 
DOI: 10.20396/zet.v29i00.8661904

Shulman, L. S. (1986). Those Who Understand: Knowledge Growth in Teaching. Educational Researcher, 15 (2), 4-14. 
DOI: $10.20396 /$ zet.v29i00.8661904

\section{Anexo 1}

Tabela 7: Porcentagem de acerto de cada uma das questões objetivas do componente específico dentre os estudantes em cada conceito.

\begin{tabular}{|l|c|c|c|c|c|c|}
\hline & Tipo de questão & Conceito 1 & Conceito 2 & Conceito 3 & Conceito 4 & Conceito 5 \\
\hline Q9 & ES & $12,44 \%$ & $21,64 \%$ & $27,18 \%$ & $51,68 \%$ & $91,07 \%$ \\
\hline Q10 & EB & $22,12 \%$ & $43,27 \%$ & $71,00 \%$ & $90,07 \%$ & $98,21 \%$ \\
\hline Q11 & ES & $11,83 \%$ & $22,95 \%$ & $37,64 \%$ & $70,95 \%$ & $87,50 \%$ \\
\hline Q12 & ES & $9,52 \%$ & $21,33 \%$ & $43,58 \%$ & $79,27 \%$ & $92,86 \%$ \\
\hline Q13 & ES & $13,36 \%$ & $27,96 \%$ & $51,48 \%$ & $72,70 \%$ & $85,71 \%$ \\
\hline Q14 & ES & $9,06 \%$ & $14,52 \%$ & $18,89 \%$ & $39,12 \%$ & $76,79 \%$ \\
\hline Q15 & EB & $12,44 \%$ & $18,48 \%$ & $31,80 \%$ & $58,69 \%$ & $91,07 \%$ \\
\hline Q16 & Anulada & - & - & - & - & - \\
\hline Q17 & EB & $11,06 \%$ & $21,59 \%$ & $32,75 \%$ & $51,53 \%$ & $67,86 \%$ \\
\hline Q18 & EB & $7,22 \%$ & $11,54 \%$ & $19,55 \%$ & $39,71 \%$ & $87,50 \%$ \\
\hline Q19 & Anulada & - & - & - & - & - \\
\hline Q20 & ES & $11,37 \%$ & $18,39 \%$ & $25,36 \%$ & $59,42 \%$ & $91,07 \%$ \\
\hline Q21 & Anulada & - & - & - & - & - \\
\hline Q22 & EB & $12,29 \%$ & $19,69 \%$ & $40,28 \%$ & $73,87 \%$ & $96,43 \%$ \\
\hline Q23 & Anulada & - & - & - & - & - \\
\hline Q24 & EB & $12,60 \%$ & $17,26 \%$ & $26,41 \%$ & $53,58 \%$ & $96,43 \%$ \\
\hline Q25 & ES & $12,14 \%$ & $25,07 \%$ & $40,99 \%$ & $60,00 \%$ & $82,14 \%$ \\
\hline Q26 & ES & $20,89 \%$ & $48,74 \%$ & $77,58 \%$ & $91,39 \%$ & $100,00 \%$ \\
\hline Q27 & ES & $14,75 \%$ & $34,19 \%$ & $60,43 \%$ & $80,15 \%$ & $96,43 \%$ \\
\hline Q28 & PE & $15,21 \%$ & $32,68 \%$ & $53,41 \%$ & $67,45 \%$ & $69,64 \%$ \\
\hline Q29 & PE & $15,67 \%$ & $27,27 \%$ & $43,42 \%$ & $60,58 \%$ & $80,36 \%$ \\
\hline Q30 & PE & $14,75 \%$ & $30,95 \%$ & $60,83 \%$ & $82,48 \%$ & $92,86 \%$ \\
\hline Q31 & PE & $13,52 \%$ & $29,49 \%$ & $48,18 \%$ & $61,02 \%$ & $76,79 \%$ \\
\hline Q32 & PE & $15,21 \%$ & $30,25 \%$ & $55,12 \%$ & $74,74 \%$ & $92,86 \%$ \\
\hline Q33 & PE & $16,90 \%$ & $32,31 \%$ & $57,69 \%$ & $77,81 \%$ & $94,64 \%$ \\
\hline Q34 & PE & $14,13 \%$ & $27,34 \%$ & $43,77 \%$ & $61,02 \%$ & $83,93 \%$ \\
\hline Q35 & PE & $24,58 \%$ & $56,27 \%$ & $81,25 \%$ & $89,78 \%$ & $92,86 \%$ \\
\hline
\end{tabular}

Observação: As questões de 1 a 8 são de conhecimento geral. Também não constam nessa tabela as 5 questões discursivas . 


\section{Anexo 2}

\section{QUESTÃO 15}

O gerente de um posto de combustíveis observou que, na primeira semana do mês em que definiu o preço do litro de gasolina a $\mathrm{R} \$$ 3,70, foram vendidos 15000 litros diários. Com isso, o posto fez uma promoção e percebeu que, para cada centavo de desconto que concedia por litro, eram vendidos 200 litros de gasolina a mais por dia.

Representando por $p$ a quantidade de centavos correspondente ao desconto dado no preço de cada litro de gasolina, e por $F$ o valor, em reais, faturado por dia com a venda de gasolina, a expressão que descreve essa situação é
(A) $F=15000+590 p-2 p^{2}$
B $F=15000+590 p+2 p^{2}$
C $F=55500-590 p-2 p^{2}$
(D) $F=55500+590 p-2 p^{2}$
() $F=55500-590 p+2 p^{2}$

Figura 4: Questão 15 do ENADE 2017 - Licenciatura em Matemática

Fonte: própria

\section{Questão 155}

Um posto de combustível vende 10.000 litros de álcool por dia a $\mathrm{R} \$ 1,50$ cada litro. Seu proprietário percebeu que, para cada centavo de desconto que concedia por litro, eram vendidos 100 litros a mais por dia. Por exemplo, no dia em que o preço do álcool foi $\mathrm{R} \$ 1,48$, foram vendidos 10.200 litros.

Considerando $x$ o valor, em centavos, do desconto dado no preço de cada litro, e $V$ o valor, em $\mathrm{R} \$$, arrecadado por dia com a venda do álcool, então a expressão que relaciona $V$ e $x$ é

A $V=10.000+50 x-x^{2}$
B $V=10.000+50 x+x^{2}$
C $V=15.000-50 x-x^{2}$
D $V=15.000+50 x-x^{2}$
ㅌ $V=15.000-50 x+x^{2}$

Figura 5: Questão 155 da prova cinza do ENEM 2009

Fonte: própria 


\section{QUESTÃO 20}

Durante o final de temporada de um evento de corrida automobilística, é comum chover nos dois dias de treino, sexta-feira e sábado, e no dia da corrida, domingo. Suponha que a previsão meteorológica para esses dias indique $80 \%$ de chance de chuva para cada um dos dias de treino e $30 \%$ de chance de chuva para o dia da corrida.

Considerando as informações do texto acima, avalie as afirmações a seguir.

I. A chance de não chover em nenhum dos três dias é de $2,8 \%$.

II. A chance de chover em pelo menos um dos três dias é de $97,2 \%$.

III. A chance de chover sexta-feira e sábado é de $80 \%$.

É correto o que se afirma em

A I, apenas.

B III, apenas.

C I e ll, apenas.

D II e III, apenas.

E I, II e III.

Figura 6: Questão 20 do ENADE 2017 - Licenciatura em Matemática

Fonte: própria

\section{QUESTÃO 138}

Um morador de uma região metropolitana tem $50 \%$ de probabilidade de atrasar-se para o trabalho quando chove na região; caso não chova, sua probabilidade de atraso é de $25 \%$. Para um determinado dia, o serviço de meteorologia estima em $30 \%$ a probabilidade da ocorrência de chuva nessa região.

Qual é a probabilidade de esse morador se atrasar para o serviço no dia para o qual foi dada a estimativa de chuva?

(A) 0,075

B 0,150

C 0,325

(D) 0,600

(E) 0,800

Figura 7: Questão 138 da prova cinza do ENEM 2017

Fonte: própria 